\title{
INVESTIGATION ON SERVICE YEARS OF LARGE RUBBER MARINE FENDERS
}

\author{
Hitoshi AKIYAMA ${ }^{1}$, Kentaro SHIMIZU², Shigeru UEDA ${ }^{3}$ and Toshiro KAMADA 4 \\ ${ }^{1}$ Member of JSCE, Dept. of Civil Eng., Osaka University (2-1 Yamadaoka, Suita-shi, Osaka 565-0871, Japan) \\ E-mail: hitoshi.akiyama@bridgestone.com \\ ${ }^{2}$ Marine Fender Developments, Bridgestone Corporation (1 Kashio-cho, Totuka-ku, Yokohama 244-8510, Japan) \\ E-mail: kentaro.shimizu@ @ridgestone.com \\ ${ }^{3}$ Fellow Member of JSCE, Professor emeritus, Tottori University \\ (2-2-2 Hayabuchi, Tsuzuki-ku, Yokohama 224-0025, Japan) \\ E-mail: ued21010@ideacon.co.jp \\ ${ }^{4}$ Member of JSCE, Professor, Dept. of Civil Eng., Osaka University \\ (2-1 Yamadaoka, Suita-shi, Osaka 565-0871, Japan) \\ E-mail: Kamada@ civil.eng.osaka-u.ac.jp
}

\begin{abstract}
Estimating the life of rubber marine fender (fender) is an important concern in the maintenance of a port facility. From the supply record of the Circular-Shaped Buckling (CSB) fender with panel contact, the actual service life was from 15 to 35 years. The compression tests of the fenders returned from ports showed that the reaction forces increased moderately due to the years in service. Other than some visible signs such as cracks and deformations, invisible signs of aging including uneven buckling, increased reaction force, and the growth of cracks were observed. The material tests results indicated that the deterioration of physical properties were limited to the rubber surface; the center of rubber bodies were still considered to be elastic and flexible. The performance in the first compression cycle of the test showed that the used fender exhibited a higher reaction force than the value stated in the catalogue - that is a value equivalent to the average of the second and third compression cycles. This increased reaction force during the first compression cycle (after a long interval from it's last compression cycle), for example, if used as inventory stock, could potentially be a concern to the berth structure and/or the vessel's hull.
\end{abstract}

Key Words : rubber fender, durability, service years, failure modes, compression test, field survey

\section{INTRODUCTION}

A fender is primarily a damper installed on the quay wall in order to absorb the large kinetic energy of a berthing ship. Before fender was developed approximately 60 years ago, timbers and old tires were used for this purpose. Since then, fenders have increased in size and type considerably in order to cater to the growing size and range of ships. This has also led to the importance of maintenance of the port infrastructure. Unfortunately, the number of studies for service life of fenders is limited. Terauchi et al. ${ }^{1)}$ reported that the service life of $\mathrm{V}$-shaped fenders was from around 10 to 20 years. This was based on verification, by the inspection of various fenders in ports around Japan. A maintenance guideline ${ }^{2)}$ was published to evaluate the remaining function of fenders by measuring the visible defects of the fender body. However the actual replacement record of large-sized fenders has not been open and no practical barometer

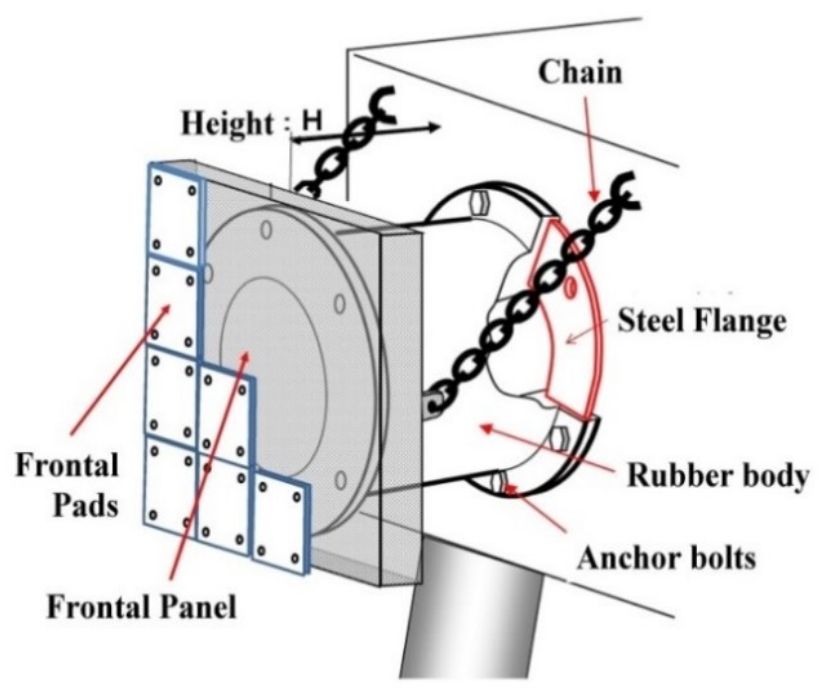

Fig.1 The Circular Shaped Buckling (CSB) fender system.

of service years exists. The unexpected failure of fenders will affect not only the cost but also the safe 
operation of a port facility. The appropriate life forecast of fenders is important. Authors looked through the supply records of the CSB fender, with frontal panel, and studied the reason for their replacements to better understand the aging effects that had resulted.

Fig.1 shows the general concept of the CSB-type fender system. The frontal panel is mounted and fixed onto the thick vertical rubber cylinder, through an embedded steel flange by nut and bolt; the weight of the frontal panel is supported by chains. The quay side of flange is fixed to the quay wall by anchor bolts. The CSB fender, which was developed in 1964, range from $400 \mathrm{~mm}(400 \mathrm{H})$ to $3 \mathrm{~m}(3000 \mathrm{H})$ in size. The total number of fenders sized $2000 \mathrm{H}$ and above is approx imately 1900 units globally.

Fig.2 illustrates the reasons for fender replacements and the factors for deteriation. The term 'service years' is defined as the years between delivery and removal of the fenders. The reason for replacement due to the external deterioration can be visually evaluated by the maintenance guideline ${ }^{2}$. In the case that fenders are deteriorating internally, therefore not visible, it becomes a hidden risk unless it is replaced as part of preventive maintenance. The items in the red box in Fig. 2 are the non-visible forms of deterioration as focused on in this paper. The fender life is determined by both visible and non-visible deteriorations. The deteriorations are caused by the environmental and operational conditions. Sulfur crosslinks in rubber break up by oxidation and become stiffer after they re-entangled, but strain such as abnormal compression also damage those linkings. As a result, the elasticity could both increase and decrease. As an environmental factor, hardening by age causes high reaction force, which could be a concern to the berth structure and ship's hull. Embrittlement of rubber could grow cracks on the surface and tear the rubber body. Note that cracks on surface are closed and not clearly visible when the fender is not compressed. They open when the fender is compressed and will tear and increase in size if the rubber deteriorates. These factors, combined with operational factors, determine the physical life of the fender.

This paper aims to clarify the actual service years of fenders and evaluate the deterioration to determine the physical life as a large rubber product in marine use. In Chapter 2, the profile of the number of unit was demonstrated in terms of service years, reason for replacement, type of ship, and type of berth structure. In Chapter 3, the compression test result of returned fenders is shown and the deterioration of fender is explained. In Chapter 4, the result of material tests derived from the dissected rubber body is discussed.

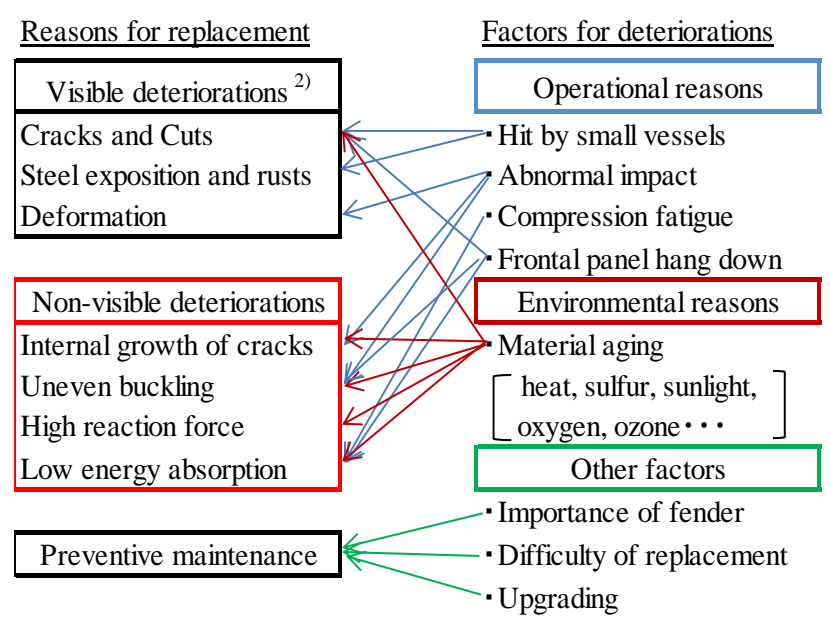

Fig.2 Reasons for fender replacement and factors.

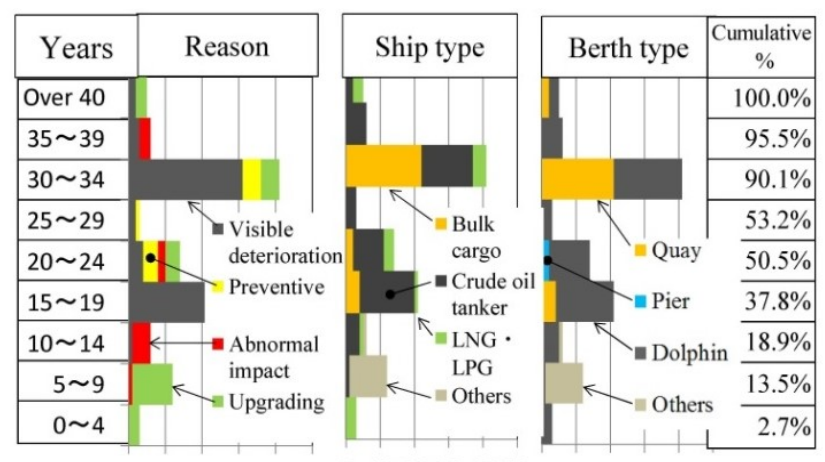

$01020304050010203040500 \quad 1020304050$

Number of replaced fenders

Fig.3 Summary of fender replacements.

\section{ACTUAL SERVICE YEARS}

In this chapter, the replacement projects of CSB fenders (sized 2 meters and above) were selected from our delivery record. The number of projects is categorized into reasons, ship types, and berth types.

The number of replacement by reasons are shown in the left column of Fig.3. "Upgrading" means that the replacements were required to facilitate larger ships. "Abnormal impact" refers to the damage caused by ships with abnormal speed or motion. The excessive berthing velocity causes the over compression and sulfur cross-linking inside rubber are cut thus the performance decreases. Also the abnormal berthing angle causes the uneven buckling. Thus fenders may be replaced if those accidents were reported. "Visible deterioration" is the replacement by visual inspection based on the maintenance guideline $^{2)}$. "Preventive" means fenders were replaced before they showed any sign of damage in order to keep the safety operation of the berth. The "Aging" has two peaks at 15 to 19 years and at 30 to 34 years while there are no clear peaks in "Upgrading" and "Abnormal impact." The center column in Fig.3 shows the 
number of replacements at each age in relation to ship types and the right column indicates berth types. The ships with fenders larger than 2 meters are generally transporting crude oil tankers or bulk cargo. In this survey, $83 \%$ of crude oil tankers use dolphin arrangement. Thus the profiles of dolphin and crude oil tanker, look similar to those of the bulk cargo and quay. The cumulative percentage indicates that $90.1 \%$ of replacements are conducted before 35 years of use.

Thus, it is concluded that the actual service years from replacement record is 15 to 35 years. Fenders situated on dolphins are likely to be changed earlier than fenders situated on a quay. Each fender had different conditions which should affect its life such as climate, geographical location, and maintenance level. The indivisual arrangements will be discussed in more detail in Chapters 3 and 4.

\section{COMPRESSION PERFORMANCE OF USED FENDERS}

A number of the used sample fenders were laboratory tested for quality when removed. In this chapter, the performances of these fenders were discussed to see how the age had changed and differed from the catalogue performance.

\section{(1) List of returned fenders}

Though the opportunity to use the old fenders tested under laboratory conditions was very limited, we managed 26 fenders in all, as shown in Table 1. Individual causes for replacement are also noted with short remarks. Degradation points are explained in Table 5 at the end of section (3).

Table 1 List of returned fenders.

Degradation points $>6$ (Non usable)

\begin{tabular}{|c|c|c|c|c|c|c|c|c|c|}
\hline $\begin{array}{l}\text { FD } \\
\text { No. }\end{array}$ & Ship type & $\begin{array}{c}\text { Fender size } \\
\text { Rubber Grade }\end{array}$ & Units & $\begin{array}{c}\text { Delivered in } \\
\text { Tested in }\end{array}$ & \begin{tabular}{|c|}
$\begin{array}{c}\text { Service } \\
\text { years }\end{array}$ \\
\end{tabular} & $\begin{array}{c}T \\
\left({ }^{\circ} \mathrm{C}\right) \\
\end{array}$ & Reason of replacement & Remarks (Non-visible deteriorations) & $\begin{array}{l}\text { Degradation } \\
\text { Points }\end{array}$ \\
\hline \multirow{2}{*}{1} & \multirow{2}{*}{$\begin{array}{l}\text { Crude oil } \\
\text { Tanker }\end{array}$} & \multirow{2}{*}{$\begin{array}{r}1600 \mathrm{H} \\
(\mathrm{R} 1)\end{array}$} & \multirow{2}{*}{2} & 2010 & \multirow{2}{*}{1} & \multirow{2}{*}{13.4} & \multirow{2}{*}{$\begin{array}{l}\text { Over compressed by tsunami of East } \\
\text { Japan Earthquake }\end{array}$} & \multirow{2}{*}{$\begin{array}{l}\text { Cuts by fixing bolts but still kept good } \\
\text { performance }\end{array}$} & \multirow{2}{*}{2} \\
\hline & & & & 2011 & & & & & \\
\hline \multirow{2}{*}{2} & \multirow{2}{*}{$\begin{array}{l}\text { Crude oil } \\
\text { Tanker }\end{array}$} & \multirow{2}{*}{$\begin{array}{r}1600 \mathrm{H} \\
(\mathrm{R} 1)\end{array}$} & \multirow[t]{2}{*}{2} & 2001 & \multirow{2}{*}{10} & \multirow{2}{*}{13.4} & \multirow{2}{*}{$\begin{array}{l}\text { Over compressed by tsunami of East } \\
\text { Japan Earthquake }\end{array}$} & \multirow{2}{*}{$\begin{array}{l}\text { Cuts by fixing bolts (Abnormal impact) but } \\
\text { still kept good performance. }\end{array}$} & \multirow{2}{*}{2} \\
\hline & & & & 2011 & & & & & \\
\hline \multirow{2}{*}{3} & \multirow{2}{*}{ Bulk cargo } & $1450 \mathrm{H}$ & 2 & 1992 & 14 & 23.1 & Visible deterioration-cracks(0.5-1.3m), & Material test, Uneven buckling, High reaction & \\
\hline & & & & 2006 & & & & & \\
\hline 4 & Crude oil & $1450 \mathrm{H}$ & 1 & 1982 & 15 & 157 & Visible deterioration-cracks, Steel & No temperature record (assumed $23^{\circ} \mathrm{C}$ ) & 3 \\
\hline 4 & Tanker & $(\mathrm{RH})$ & 1 & 1997 & 15 & 15.1 & exposition and rust & No temerature recora (assumed $23{ }^{\circ}$ ) & 3 \\
\hline 5 & J NG Carrior & $2000 \mathrm{H}$ & 1 & 1988 & 1 & 152 & Preyentive mintenance & Material test, Light uneven buckling, Surface & 4 \\
\hline 3 & LNG Cartior & $(\mathrm{R} 0+10)$ & 1 & 2009 & 21 & 15.2 & Preventive maintenance & cracks. & 4 \\
\hline & & $800 \mathrm{H}$ & 2 & 1992 & & & Preventive maintenance & High reaction force $(+13$ & \\
\hline 6 & Pontoon & $(\mathrm{RH}, \mathrm{R} 1)$ & 2 & 2014 & 22 & 15.8 & (with Pontoon maintenance) & good performance & \\
\hline 7 & Pontoon & $630 \mathrm{H}$ & 1 & 1992 & 22 & 168 & Preventive maintenance & High reaction force (+10\%) but still kept & \\
\hline 1 & (Oil barrior) & (RH) & & 2014 & 22 & 10.0 & Freventive mantenance & & \\
\hline 8 & Car Carrier & $800 \mathrm{H}$ & 2 & 1981 & 25 & 17.0 & Visible deterioration-steel exposition & Material test, Uneven buckling, & \\
\hline & & (R0) & & 2006 & & & and rust & & \\
\hline 9 & LNG Carrior & $\begin{array}{r}1700 \mathrm{H} \\
(\mathrm{RE})\end{array}$ & 1 & $\begin{array}{l}1983 \\
2010\end{array}$ & 27 & 15.7 & Preventive maintenance & $\begin{array}{l}\text { Material test, Surface crack but kept good } \\
\text { performance. }\end{array}$ & 3 \\
\hline & & $2000 \mathrm{H}$ & & 1977 & & & Preyentive mintenance & Material test, Surface crack, High reaction & \\
\hline 10 & LNG Carrior & $(\mathrm{R} 1)$ & 4 & 2007 & 30 & 15.2 & Preventive maintenance & force $(+23 \%$ & \\
\hline 11 & Crude oil & $3000 \mathrm{H}$ & 1 & 1975 & 32 & 152 & Preventive mintenance & Material test, Test discontinued by severe & \\
\hline 11 & Tanker & $(\mathrm{R} 0-10)$ & 1 & 2007 & 32 & 15.2 & & cracks and uneven buckling. & \\
\hline 12 & Bulk cargo & $1000 \mathrm{H}$ & 2 & 1978 & 32 & 16.4 & Visible deterioration-steel exposition & Severe cracks, Test discontinued by too high & \\
\hline & & & & 2010 & & & & & \\
\hline 13 & Crude oil & $2250 \mathrm{H}$ & 1 & 1971 & 30 & 164 & Visible deterioration-cracks of & High reaction force $(+11 \%)$, Light uneven & \\
\hline & Tanker & (R0) & & 2010 & & & abnorm & bucl & \\
\hline 14 & Crude oil & $3000 \mathrm{H}$ & 1 & 1974 & 39 & 152 & Visible deterioration-cracks & Test discontinued by uneven buckling, cracks & \\
\hline & $\mathrm{Ta}$ & $(\mathrm{R} 0-10)$ & & 2013 & & & & ction force $(+20 \%$ & \\
\hline 15 & Bulk caroo & $1000 \mathrm{H}$ & 2 & 1970 & 40 & 164 & Visible deterioration-cracks & Test discontinued by too high reaction force & \\
\hline & & (R0) & & 2010 & & & & $(+37$ & \\
\hline 16 & Crude oil & $2000 \mathrm{H}$ & 1 & 1970 & 42 & 152 & Visual deterioration-cracks & Test discontinued by extreme uneven & \\
\hline & Tanker & (R1) & 1 & 2012 & & & & buckling & \\
\hline
\end{tabular}

Note : "Material aging" means the fender was dissected for material tests.

Temperature was not recorded for FD No.4, 5, 8, 10, and 14 so the average temperature record ${ }^{3)}: \boldsymbol{T}$ was used.

The rubber grade is the grade of hardness in order as: $\mathrm{RE}>\mathrm{RH}>\mathrm{R} 0+10>\mathrm{R} 0-10>\mathrm{R} 1$

Degradation Points is the degree of degradation explained in Table 5 (non usable over 6 points with red circle) 


\section{(2) Performance and deformation}

Table 2 shows the performance curves for midsized to large fenders based on 10-year intervals. The performance results for the first compression cycle test are expressed in blue dots and dashed lines. The average of the second and third compression cycle are in red dashed lines. The catalogue values are in black solid lines. "The average of the second and third compression is used as a standard performance which must be within $\pm 10 \%$ deviation of catalogue's value.

Table 2 Performances of fenders in 10-year generations.

Non usable

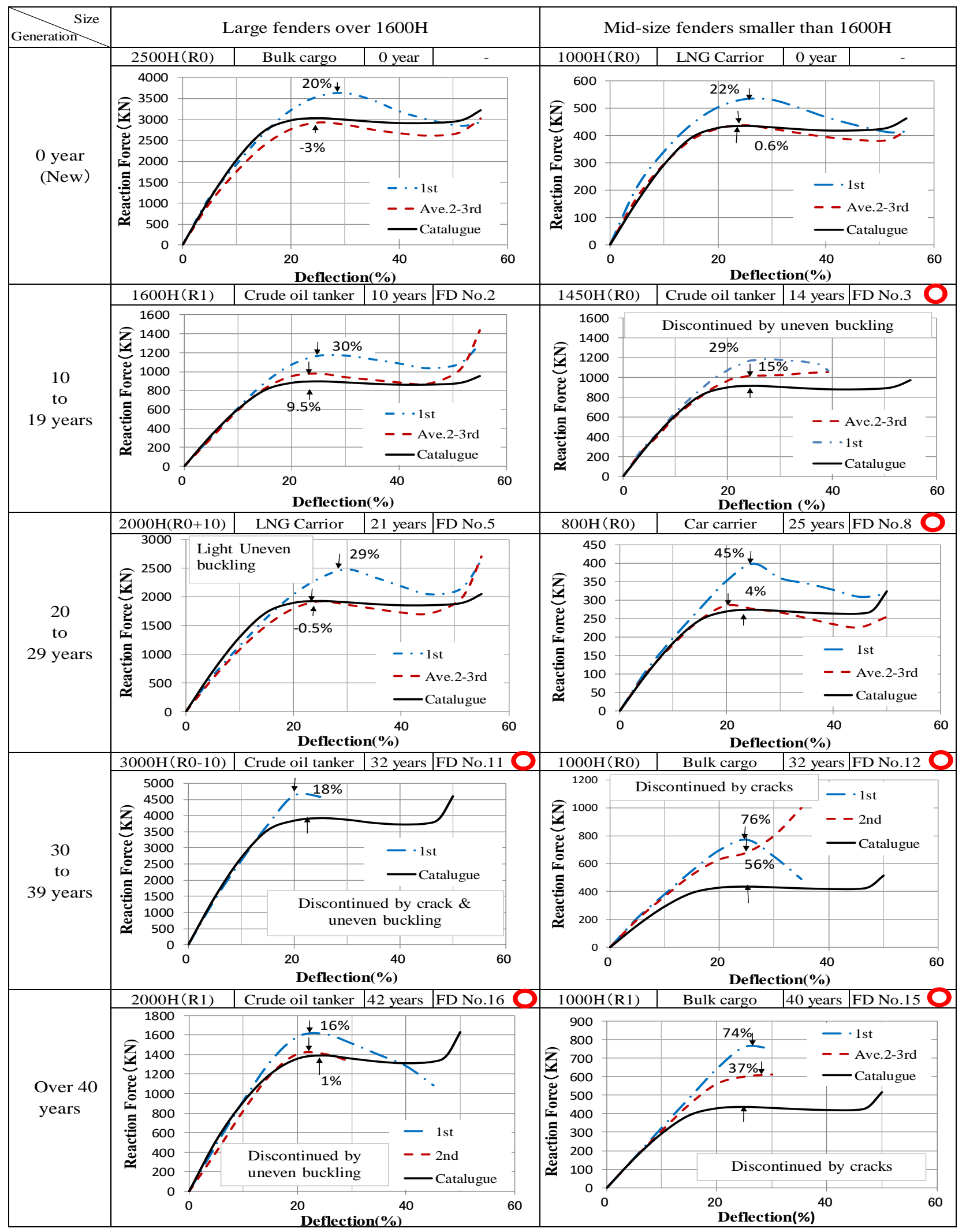


Table 3 Photos of cracks and bucklings under compression.

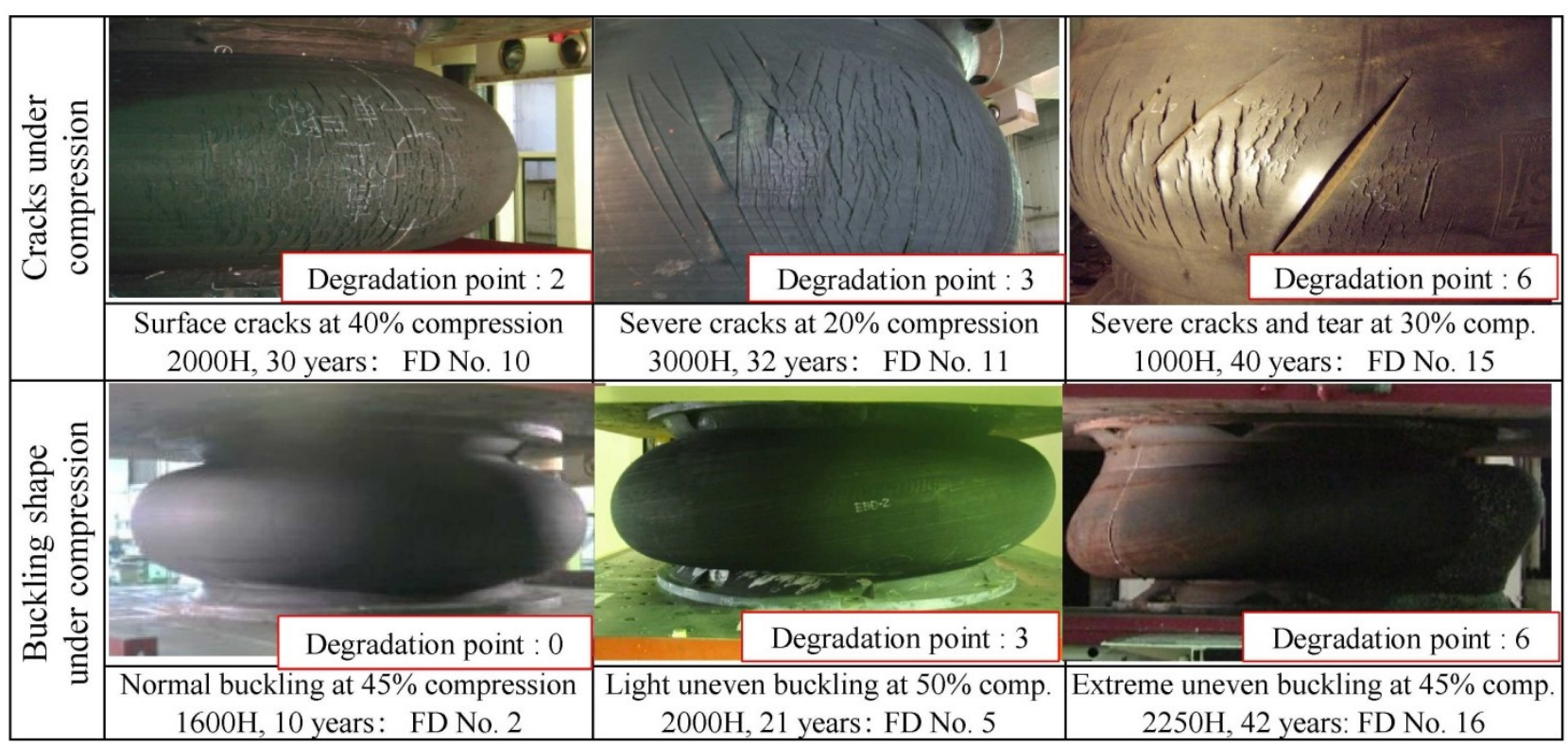

The compression test procedure was based on the PIANC 1980 guidelines ${ }^{4}$ as follows:

1. Total 3 times compression with about 5-minute intervals at the speed from 2 to $8 \mathrm{~cm} / \mathrm{s}$.

2. The first compression is called the stress relax ation cycle and data are ignored.

3. The average of second and third values are regarded as the standard value.

Zero (0) year is the example of the shipping inspection tests of a new product. Note that the $1600 \mathrm{H}$ - (FD No.2) sized fender was included in the large sized category owing to lack of record of a fender larger than the $2000 \mathrm{H}$ in 10 to 19 years section. The red circle at the upper right corner indicates that the fender is regarded as unusable.

Since those tests have been conducted over such a long period, old figures were converted to a common expression in the following manner:

1. The performance is affected by temperature. Thus performances are corrected to $23{ }^{\circ} \mathrm{C}$ by temperature factors. If test temperature had not been recorded, the average temperature of the day of testing in the Japan Meteorological Agency website ${ }^{3)}$ was used. If even the test date was unknown, $23^{\circ} \mathrm{C}$ was assumed (FD No.4).

2. All dimensions were converted to the SI unit assuming the gravity was $9.81 \mathrm{~m} / \mathrm{s}^{2}$.

\section{(3) Deterioration modes under compression}

Here, visual and non-visual symptoms of aging are explained. Table 3 provides examples of the growth of cracks and the buckling effect when the fenders were compressed. In coastal areas, oxygen and ozone break the polymer links by destroying the hydrogen
Table 4 Reasons of uneven buckling.

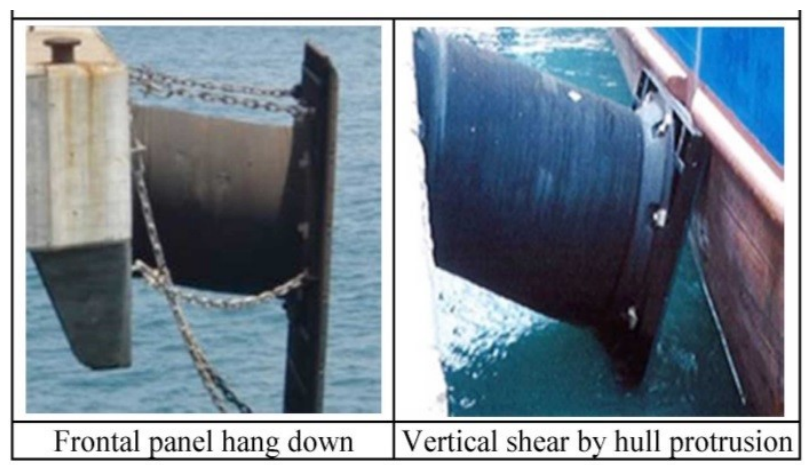

molecules from the surface of the rubber.Skin rubber loses its flexibility and cracks open when the outer surface is stretched by fender compression. The body rubber (under the skin) also deteriorates and becomes harder and inflexible. Thus, the surface cracks become larger throughout the whole body. The upper right photo in Table 3 shows the expanded crack prior before the test was stopped. These cracks occur mainly on the upper side of the body where the rubber has more sunlight. "Uneven buckling" is the asymmetric deformation when the fender deforms sideways. As a result, the reaction force reduces after the peak as shown in FD No. 12 and FD No. 16 in Table 2. The reduction of reaction force would reduce the energy absorption. There are many reasons for uneven buckling other than abnormal angular berthing as stated in Chapter 2. The weight of fender body and frontal panel always pulls the top of fender downwards especially when the weight support chains are loose as shown in the left photo in Table 4. Also the protrusion of the ship belt sometimes pushes the 
Table 5 Degradation points of each mode.

\begin{tabular}{|c|c|c|c|}
\hline Modes & Light & Medium & Severe \\
\hline \multirow{2}{*}{ Crack length } & 2 & 3 & 6 \\
\hline & \multicolumn{3}{|c|}{ See Table 3} \\
\hline \multirow{2}{*}{ Uneven buckling } & 2 & 3 & 6 \\
\hline & \multicolumn{3}{|c|}{ See Table 3} \\
\hline \multirow{2}{*}{$\begin{array}{l}\text { High reaction } \\
\text { force rate: } C_{R}\end{array}$} & 0 & 3 & 6 \\
\hline & $C_{R}<10 \%$ & $10 \% C_{R}<R m$ & $R m<C_{R}$ \\
\hline \begin{tabular}{|l|} 
Test discontinued \\
\end{tabular} & \multicolumn{3}{|c|}{6} \\
\hline
\end{tabular}

frontal panel down while the ship is moored and loading cargo, which is shown in the right photo in Table4. The vertical permanent deformation is recommended is recommended by the manufacturer to be less than $3 \%$ of fender height to maintain the performance. These factors could shorten the actual service life, therefore both physical and chemical consideration in design, operation, and maintenance are very important. In Table 2, the tests after 30 years were discontinued mainly by uneven buckling for large fenders, and by the increases in the cracks for midsized fenders. These fenders were now performing too far from their original specification and therefore deemed unusable; the decision to replae the fenders was proven correct. The uneven buckling observed at FD No.5 (2000H, 21 years) was very minor. It was reported that this fender was rotated 180 degress in order to cancel the asymmetry of gravity and sunlight. This consideration should have improved the service life of this fender. Another exception is FD No.3 which showed uneven buckling and $15 \%$ increase in reaction force after only 14 years. This berth is located in the south island of Japan where the average temperature is $23^{\circ} \mathrm{C}$ which is from 7 to $8{ }^{\circ} \mathrm{C}$ higher than in other parts of $\mathrm{Japan}^{3)}$ as shown in Table 1. High temperatures accelerated the aging of FD No.3. This will be discussed further in Chapter 4 . The rate of material aging by external factors such as sunlight and oxygen of large-sized fenders is slower than mid-sized fenders due to the rubber thickness. Therefore, the increase in reaction force of large fenders is relatively small. On the other hand, according to a simple beam theory, assuming the fender is mounted to the quay in the normal horizontal fashion, the vertical (drooping) deflection effect at the frontal panel end is relative to scale and therefore the larger the fender/frontal frame is, the greater the drooping effect. This is one of the reasons why the uneven buckling was more evident in large fenders. In Table 2, the reaction forces of mid-sized fenders exceeded the $10 \%$ manufacturing tolerance after 30 years. The uneven buckling may reduce the reaction force potentially canceling out the rubber hardening in large

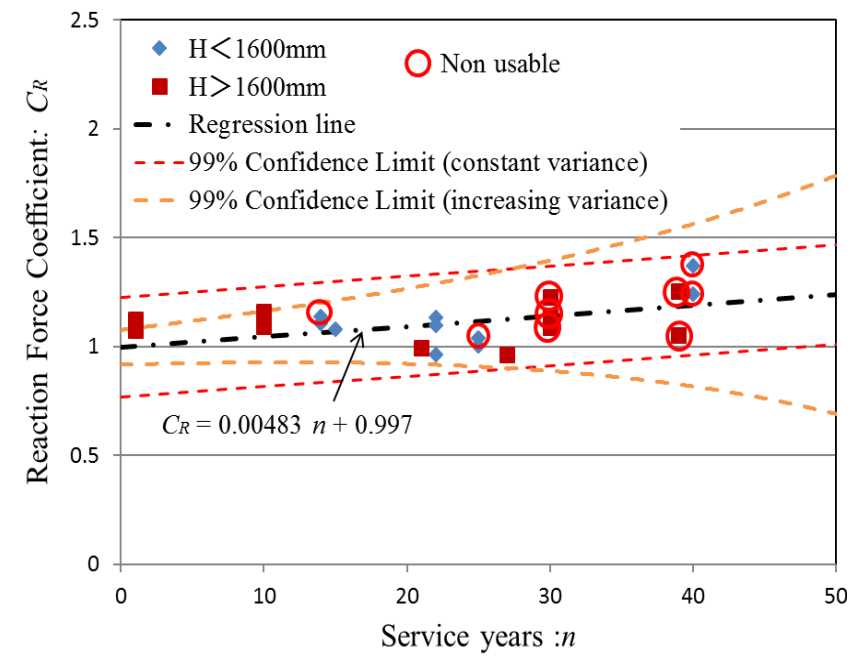

Fig.4 Reaction Force Coefficient by age: $C_{R}$ (Average of $2^{\text {nd }}-3^{\text {rd }}$ compression at $25 \%$ ).

fenders, but it should be warned that there are nonvisible aging effects other than reaction force and 30 years is a reasonable time for replacing fenders.

The deterioration point is defined as shown in Table 5 in which the fender scoring more than 6 points is considered "Non-usable". The basis of these points is from visual evaluation explained in the maintenance guideline ${ }^{2)}$. $R m$ in Table5 is difined as the total of aging impact and $10 \%$ manufacturing tolerance.

\section{(4) Reaction force coefficient by age: $C_{R}$}

For instance, dolphins and piers supported by piles are sensitive to horizontal load thus the maximum fender reaction force is used for the design criteria. Therefore, it is important to estimate the years until the reaction force exceeds the design load to determine the service years of fender. In Table 2, the tendency of the reaction force by age is not clear because they differ by size, rubber grades and manufacturing tolerance $( \pm 10 \%)$. Thus, the Reaction Force Coefficient: $C_{R}$ is defined as follows;

$$
C_{R}=R_{P} / R_{S}
$$

$C_{R}$ : Reaction force coefficient.

$R_{P}$ : The peak reaction force of used fenders.

$R_{S}$ : The rated reaction force at $25 \%$ deflection ofstandard performance.

Fig.4 shows the reaction force coefficient by service years. The average of $C_{R}$ plots indicates a slight increase with a tendency to spread to the right; this is relative to the number of years in service. The blue inclined square plots are mid-sized fenders smaller than $2 \mathrm{~m}$ in height and the red square plots means large-sized fenders over $2 \mathrm{~m}$ high. The plot with red circle means the fender was judged already unusable based on the degradation points in Table 5. FD No.11 
(32 years), No.12 (32 years), No.15 (40 years), and No.16 (42 years) were also non-usable but not plotted in Fig.3 as they could not be compressed three times. The average annual rate of $0.483 \%$ per year is based on the assumption that the initial value was 1.0 , per the catalogue value. The maximum serviceable years obtained from the test results was approximately 30 years with two exceptions; the smaller-sized FD No.4 and FD No. 8 because they showed uneven buckling and the signs of abnormal berthing (cut by the fixing bolt and exposed steel). Thus, the past abnormal berthing is supposed to be the reason for these early uneven bucklings rather than the dead weight of the frontal panel. The red dashed lines are upper and lower limit of $99 \%$ confidence interval. Conventionally, they are two straight lines running parallel to the average regression line. The plots indicate a spread towards the right and an increase in the deviation by the number years. The environment and conditions of use are different in every fender, thus it is understood that the range of variance spreads wider by service years. It is reasonable to express the confidence values by extending the range of variance in relation to service years. To simplify the phenomenon, the variance was assumed to increase by service years and the maximum likelihood method was used.The increasing variance is expressed by equation (2):

Here,

$$
\sigma_{n}=\exp \left(\beta_{0}+\beta_{1} x_{n}\right)
$$

$\sigma_{n}$ : Variance of $C_{R}$ at $x_{n}$

$\beta 0$ : Y-intercept of variance

$\beta 1$ : First constant of variance

$x_{n}$ : Service years

Now, the probability of $x_{n}$ as the Normal distribution is assumed by equation (3):

$$
f\left(x_{n}\right)=\frac{1}{\sqrt{2 \pi \sigma_{n}^{2}}} \exp \left(-\frac{\left(x_{n}-\mu\right)^{2}}{2 \sigma_{n}^{2}}\right)
$$

Table 6 Values of parameter $\beta$.

\begin{tabular}{|c|c|c|c|}
\hline Confidence Value & $\beta 0$ & $\beta 1$ & $\beta 2$ \\
\hline $99 \%$ & -3.4719 & 0.0385 & 2.5758 \\
\hline
\end{tabular}

Table 7 Reaction force coefficient by years:

(Constant variance and increasing variance).

\begin{tabular}{|c|l|c|c|c|c|c|}
\hline \multicolumn{2}{|c|}{ Service years } & 10 & 20 & 30 & 40 & 50 \\
\hline \multicolumn{2}{|c|}{ Average } & 1.05 & 1.09 & 1.14 & 1.19 & 1.24 \\
\hline \multirow{3}{*}{$\begin{array}{c}99 \% \text { Confidence Interval } \\
\text { with constant variance }\end{array}$} & Variance: $\sigma$ & 0.09 & 0.09 & 0.09 & 0.09 & 0.09 \\
\cline { 2 - 7 } & Upper limit & 1.27 & 1.32 & 1.37 & 1.42 & 1.47 \\
\cline { 2 - 7 } & Lower limit & 0.82 & 0.86 & 0.91 & 0.96 & 1.01 \\
\hline \multirow{3}{9}{$\begin{array}{c}99 \text { Confidence Interval } \\
\text { with increasing variance }\end{array}$} & Variance: $\sigma$ & 0.05 & 0.07 & 0.10 & 0.14 & 0.21 \\
\cline { 2 - 7 } & Upper limit & 1.16 & 1.27 & 1.40 & 1.56 & 1.79 \\
\cline { 2 - 7 } & Lower limit & 0.93 & 0.92 & 0.89 & 0.82 & 0.69 \\
\hline
\end{tabular}

Here, $\mu$ is the average of $x_{n}$. Then, the likelihood of the simultaneous occurrence of $x=\left(x_{1}, x_{2} \ldots x_{n}\right)$ is expressed as equation (4):

$$
L(\beta \mid x)=\coprod_{n=1}^{26} f\left(x_{n}\right)
$$

The value of $\beta_{0}$ and $\beta_{1}$ are obtained by numerical solution to maximize the value of $L(\beta \mid x)$. The confidence interval of $C_{R}$ are expressed as follows:

$$
\begin{aligned}
& \text { Upper limit: } C_{R}=\alpha x_{n}+\delta+\beta 2 \sigma_{n} \\
& \text { Lower limit: } C_{R}=\alpha x_{n}+\delta-\beta 2 \sigma_{n}
\end{aligned}
$$

Here,

$$
\begin{aligned}
& \alpha: \text { Gradient of } C_{R} \\
& \delta: \text { Y-intercept of } C_{R} \\
& \beta_{2}: \text { Confidence of variance of normal distribution } \\
& \sigma_{n} \text { : Variance of } C_{R} \text { defined by equation(2) }
\end{aligned}
$$

The standard manufacturing tolerance is 0.9 to 1.1 . Ueda et al.5) reported the statistic average was 0.997 with 0.031 standard variance. This means $99 \%$ confidence interval is from 0.917 to 1.077 . Assuming the initial $C_{R}$ is 0.997 and the limit is from 0.917 to 1.077 at the time of delivery of fenders, the values of $\beta$ are in Table 6. Table 7 shows the characteristics values of the reaction force coefficient: $C_{R}$ by service years. Focusing on the 30 service years after which all fenders were non-usable as shown in Fig.4, the average increase in reaction force is $+14 \%$ and $99 \%$ upper limit is $+37 \%$ and $40 \%$, while the lower limit is $-9 \%$ and $-11 \%$ at 30 years, respectively in Table 7 . The increasing variance varies in a wider range than the conventional constant variance method after 30 years. Note that each plot still has $\pm 10 \%$ variance from catalogue value due to the manufacturing tolerance.

\section{(5) High reaction force "re-hardening" after a long interval}

Vulcanization is the condition in which the rubber gets high elasticity by sulfur crosslinking between polymer molecules. Some of the links are weaker than others and easily cut when they are stretched. The PIANC 2002 guidelines ${ }^{6}$ require that the newly vulcanized fender must be compressed three times in which the first compression is to cut the insufficient links between rubber molecules. This is called the stress relaxation compression and this performance data is not used. In Table 2, the first compressions after returning from site are showing to be significantly higher than the average of second and third reaction forces. The first compression's high reaction 
force was considered to have been eliminated by the stress relaxation compression when it was manufactured. This increase in reaction force looks like "restoration" after a long interval. The mechanism in the fender performance has not been clarified yet but the chemical phenomenon was first reported by Mullins ${ }^{7)}$ who stated that the recovery rate towards the initial properties differed by temperature and compoundings of rubber. The recovery speed is very slow in normal temperature. It is not likely that the recovery exceeds the initial properties, thus this re-hardening could be the combination of the recovery after an interval and the material hardening by age. As shown in Table 2, the reaction force of $800 \mathrm{H}$ with $45 \%$ increase after 25 years, and the $30 \%$ increase for the $1600 \mathrm{H}$ after only 10 years cannot be ignored with respect to the berth structure and ship hull strength even though it applies to the first compression only. The duration from the latest berthing to the compression test were unknown for the fenders in Table 2. Generally, fenders are likely to be compressed within a week or one month. However, some countermeasures such as controlling the berthing velocity, or extra compression at the manufacturer's facility might be considered for some cases such as the re-use of inventory fenders.

\section{MATERIAL TESTS}

The following five returned fenders out of Table 1 were cut to take out the rubber blocks:

FD No. $3: 1450 \mathrm{H}$ after 14 years

FD No. $8: 800 \mathrm{H}$ after 25 years

FD No. $9: 1700 \mathrm{H}$ after 27 years

FD No.10: $2000 \mathrm{H}$ after 30 years

FD No.11: $3000 \mathrm{H}$ after 32 years

The material samples of $2 \mathrm{~mm}$ thickness were made by slicing the rubber blocks in order to see how aging affects the thick rubber wall. This procedure is illustrated in Fig.5. The upper side had been facing the sky and the lower side had been facing down to the sea water.

\section{(1) Test procedure}

Samples are tested by the following procedure found in the Japanese Industrial Standards:

Hardness (deg): JIS K6253-3 Type A

Tensile strength(MPa): JIS K6251 Type 3

Elongation at break(\%): JIS K6251 Type 3

\section{(2) Profile of material properties}

As the example of material test results, the distribution of material properties of FD No.11 are shown in Fig.6. The Y-axis represents hardness and tensile

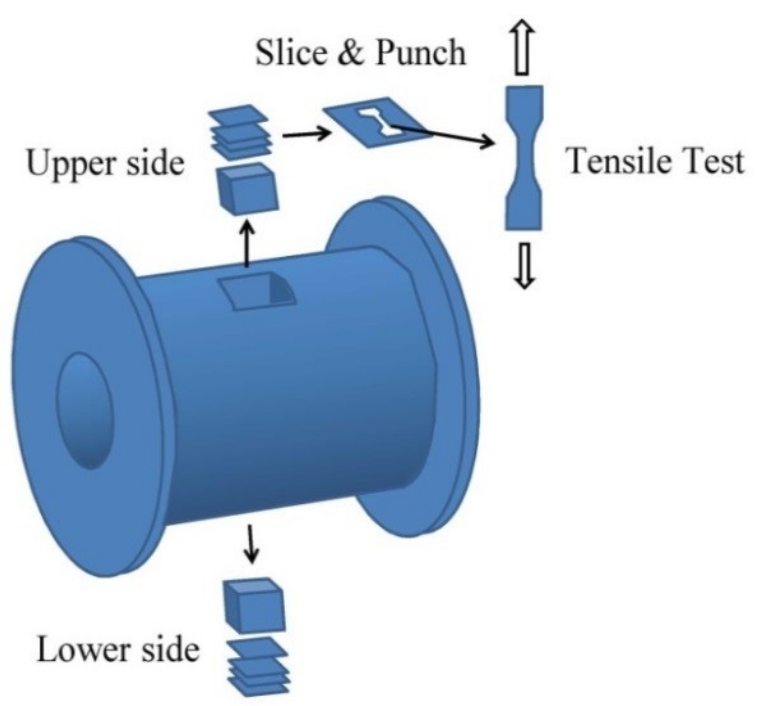

Fig. 5 Rubber sampling from returned fenders.

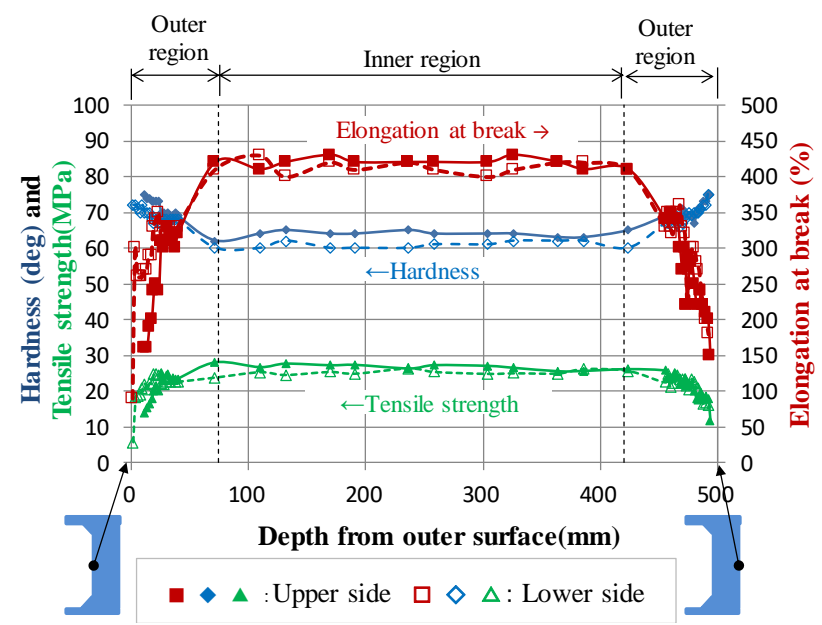

Fig.6 Distribution of material properties of FD No.11: $3000 \mathrm{H}(\mathrm{R} 0-10)$ after 32 years.

strength (measured in MPa). The second Y-axis represents the elongation breaking point (measured in \%). The X-axis represents the depth from outer surface, hence $0 \mathrm{~mm}$ is the outer surface and $495 \mathrm{~mm}$ (Ex. FD No.11:3000H) means the inner surface of the hollow cylinder. The solid lines with solid plots show the data obtained at the upper side and the broken lines with empty plots show the ones obtained at the lower side. Both look similar except that about 10 $\mathrm{mm}$ of outer surface where the elongation breaking point of the upper side is lower than that of the lower side. The effect of sunlight is shown only in the upper side surface. Rubber deteriorates from the surface by the effects of sunlight, heat, oxygen, ozone, and so on. It starts from the surface and makes the rubber stiff and brittle and resulting in higher hardness, lower tensile strength, and shorter elongation. Itoh et al. ${ }^{8}$, defined two regions of rubber from the used bridge bearing: outer and inner, and reported that the 


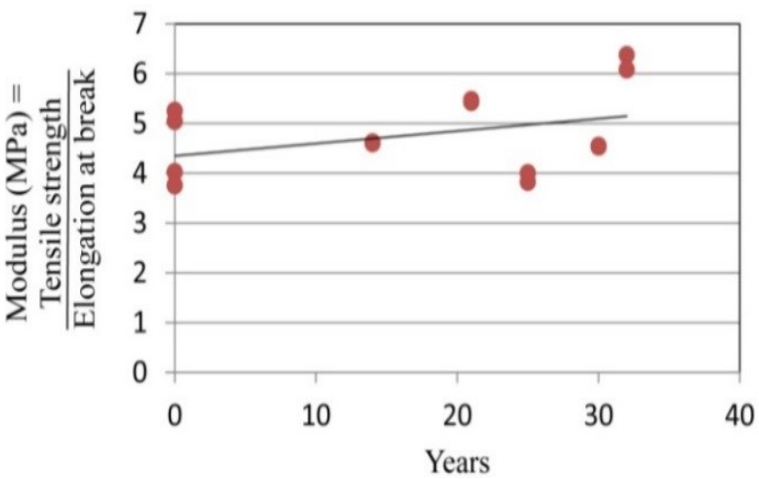

Fig.7 Aging of modulus of inner region: (Average tensile strength) / (Average elongation at break).

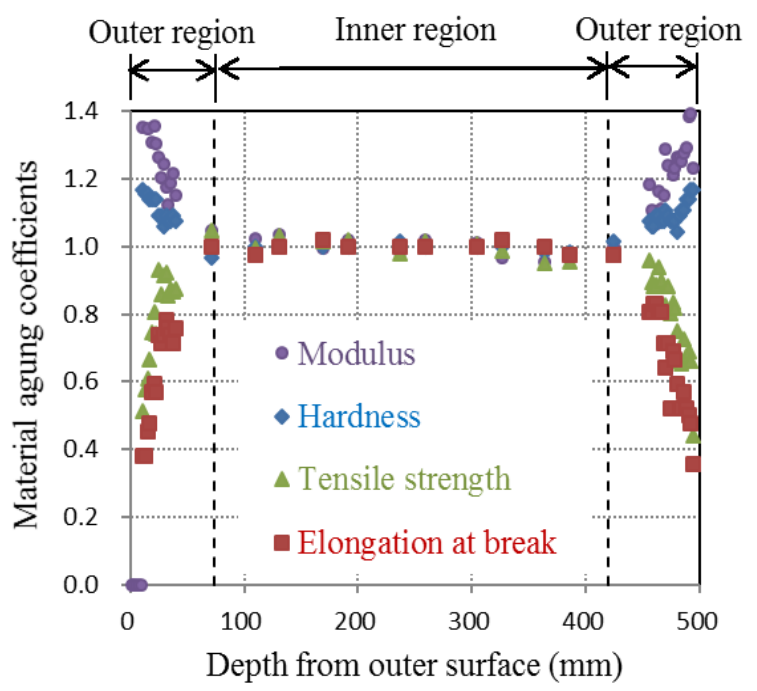

Fig.8 Distribution of material aging coefficient: FD No.11 $3000 \mathrm{H}(\mathrm{R} 0-10), 32$ years, Upper side.

property in the outer region deteriorates but does not extend to the inner region. The thickness of the outer region is called the critical depth: $d_{c}$ which is proportional to the exponent of reciprocal of temperature as shown in equation (7):

$$
d_{c}=\alpha_{c} \exp \left(\frac{\beta_{c}}{T}\right)
$$

Here,

$$
\begin{aligned}
& d_{c}: \text { Critical depth }(\mathrm{mm}) \\
& \alpha_{c}: \text { Constant }\left(=8.0 \times 10^{-4} \mathrm{~mm}\right) \\
& \beta_{c}: \text { Constant }\left(=3.3 \times 10^{3} \mathrm{~K}\right) \\
& T: \text { Absolute temperature }(\mathrm{K})
\end{aligned}
$$

In Fig.6, the critical depth is approximatly $70 \mathrm{~mm}$ from both the outer and inner surface of the body. As shown in Table 1 and Table 2, FD No.11 was evaluated "Non-usable" because it could not be tested properly due to the cracks and uneven buckling. However, the physical properties of the inner region,

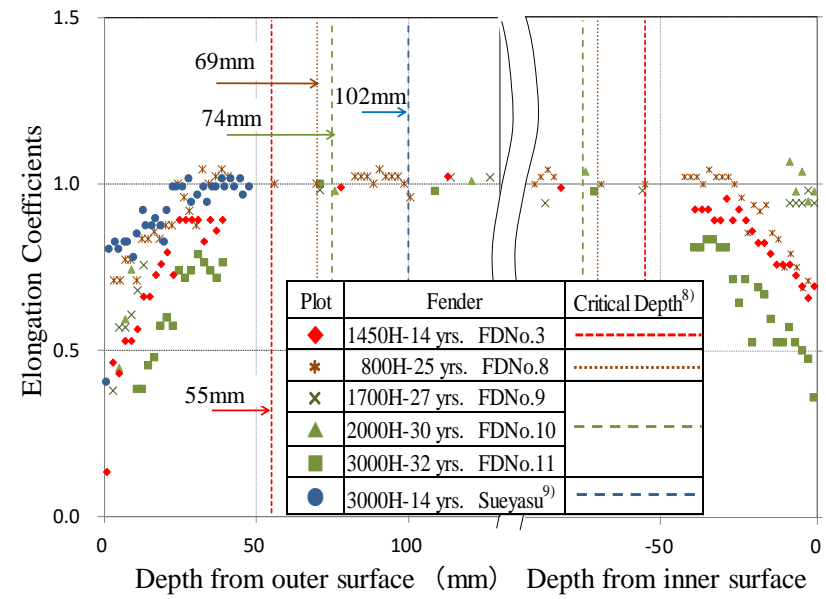

Fig.9 Elongation coefficients of returned fenders near surface (Upper side).

as shown in Fig.6, shows little deterioration. The service life of this fender may have been affected by the operational conditions rather than the material aging; therefore, a longer serviceable life may have been achieved if a different operational method was used. The initial value of rubber properties has a wide range of deviation due to the following facts:

1. Type of rubber grade compound

2. Manufacturing variance

3. Variance of cut sample quality from fender

4. Minor changes to recipe made in the past

5. Difference in vulcanizing condition between sample sheet and actual product.

For reference, the example of modulus (Tensile strength/Elongation at breaking point) in relation to service years is shown in Fig.7. The modulus plots of each year are the sampling depths, which mean values of the inner region of the fender rubber bodies. The values at year 0 are the record of the quality test when manufactured. The rubber compounding has been modified a couple of times in the past thus it varies in the range of about $20 \%$. Though the inner part of the rubber has no exposure/contact with oxygen, Fig. 7 indicates a moderate increase and Fig.4 indicates an increase in reaction force. The variance of material also affects the variance of reaction force. The reason being that the free sulfur slowly re-entangles in links at normal temperature without the supply of oxigen. In order to discuss the aging impact of rubber, the material aging coefficient is used by dividing the property data (hardness, tensile strength, and elongation at breaking point) by the average value of the inner region. Fig.8 is the material aging coefficient of FD No.11. Modulus in the outer region rises as it approaches the surfaces. Fig.8 suggests that the coefficient of elongation at breaking point shows the distribution most clearly. Then, the comparison with other fenders are shown in Fig.9. Sueyasu' ${ }^{9)}$ reported 
the deterioration of 14 years in north Japan penetrated 20 to $30 \mathrm{~mm}$. This is smaller than $70 \mathrm{~mm}$ in Fig.6 and Fig.8. The difference in average temperature between the north area and FD No.3 in the south island is about $15^{\circ} \mathrm{C}^{3)}$ which might be the reason for this difference in elongation coefficient. The calculated critical depths by Itoh et $\mathrm{al}^{8)}$ at each site location are shown in Fig.9. They look close to the measured distribution of FD No.8, 9, 10, and 11 (from 55 to $74 \mathrm{~mm}$ ) in Fig.9 except for the $3000 \mathrm{H}-14$ years in the north area where the critical depth is $102 \mathrm{~mm}$. Since the density of the data at the boundary between outer and inner region is insufficient, the exact critical depth cannot be clearly declared. However, in the coastal condition of Japan's climate, the average critical depth appears to be around $70 \mathrm{~mm}$. The distribution of deterioration becomes flat at the area deeper than the critical depth. Thus, the material life is considered "still usable" after 30 years of service. On the other hand, smaller fenders (Ex. body thickness $<140 \mathrm{~mm}$ ) will have more deterioration in the whole body. This is also suggested in Table 2 which shows that smaller fenders have higher reaction forces.

It would be convenient if we could take a small rubber sample from the fender surface on a quay wall and evaluate the aging non-destructively. However, the above material tests indicate that it would be difficult because the aging at surface and its penetration may not be a simple reaction linear to time and temperature.

\section{CONCLUSIONS}

(1) The service years of the Circular-Shaped Buckling fender from the supply record was about 15 years to 35 years.

(2) The compression tests of the returned CircularShaped Buckling fender showed that all fenders over 30 service years had lost their normal performance. There was a moderate increase in reaction force by service years but the effect of cracks and uneven buckling mitigated this increase.

(3) The rubber deterioration progressed by service years and by high temperature climate. It was limited within the critical depth, which was around $70 \mathrm{~mm}$ from the surface and the deterioration of inner region was little even after 32 years. The small fenders had more aging impact than large fenders.

(4) The compression tests of returned fender indicated that, after returning from site, the first compression may have had a higher reaction force than the initial value used for the design load.

This study was conducted only on CSB fenders. If the basic material and function were the same, then we would suggest that the aging effects will be similar to other types of fenders with frontal panel. However, quantitative data such as number of years and material property changes will be needed to confirm this.

ACKNOWLEDGMENTS: The authors would like to thank Dr. N. Murota, N. Yamaguchi, S. Kajigaya, and other members of Bridgestone Corporation for their continuous support in the gathering and disclosing of old and precious records. They also thank Prof. K. Kaito of the Department of Civil Engineering and Mr. Y. Ninomiya of the Graduate School of Engineering, Osaka University for their precious advice in the statistic data processing.

\section{REFERENCES}

1) Terauchi, K., Koizumi, T., Yamamoto, S. and Hosokawa, K.: The Deterioration actual state and the function evaluation on the rubber fender, Tech. Notes of the Port and Harbor Research Institute, No. 878, 1957. (in Japanese)

2) CDIT: Gomubougenzai no Ijikanri Guideline, Coastal Development Institute of Technology Library, No.40, Mar. 2013. (in Japanese)

3) Japan Meteorological Agency: http://www.data.jma.go.jp/ gmd/cpd/cgi-bin/view/index.php, Accessed June 29, 2015.

4) Japan section of PIANC: Report of the Japanese commission for the design of fender systems, Permanent International Association of Navigation Congress, pp. 122-124, Mar.1980. (in Japanese)

5) Ueda, S., Umemura, T., Shiraishi, S., Yamamoto, S., Akakura, Y. and Yamase, S.: Toukeiteki Syuhou niyoru Senpaku Setsuganyou Bougenzai no Sekkei nikansuru Kenkyu, Proceedings of Coastal Engineering, JSCE, Vol. 47, pp. 866-870, 2000. (in Japanese)

6) MarCom Working Group 33: Guidelines for the design of fenders system, International Navigation Congress, 2002.

7) Mullins, L.: Effect of stretching on the properties of rubber, Journal of Rubber Research, Vol. 16, pp. 275-289, 1947.

8) Itoh, Y., Gu, H., Satoh, H. and Kutsuna, Y.: Long-term determination of high damping rubber bridge bearing, Doboku Gakkai Ronbunsyuu A, Vol. 62, No. 3, pp. 595-607, 2006.

9) Sueyasu, T.: Long term aging and life forecast of large rubber products, Proc. of $141^{\text {th }}$ Rubber Technology Symposium, pp. 27-36, 2008. (in Japanese) 